\title{
The cardiovascular safety of methylphenidate
}

\author{
(ब) $(\mathbb{Q})$ OPEN ACCESS \\ What to make of studies that agree to disagree
}

\author{
John W Jackson research fellow \\ Department of Epidemiology, Harvard T.H. Chan School of Public Health, Boston, MA, USA
}

In the United States alone, 6.4 million children received a diagnosis of attention-deficit/hyperactivity disorder (ADHD) in 2011. Of these, 3.5 million received a stimulant drug, typically methylphenidate. ${ }^{1}$ In addition, there is off label use of stimulants for milder attention problems. The cardiac safety of stimulants, which are known to slightly raise blood pressure and accelerate the heart rate, has been hotly debated as case reports, ${ }^{2}$ and conflicting evidence has emerged over time. ${ }^{3}$

A linked paper by Shin and colleagues (doi:10.1136/bmj.i2550) reports on data from the first case only study of cardiovascular risk with methylphenidate. ${ }^{4}$ Using the South Korea National Health Insurance Database, the authors extracted data on 1224 cases of adverse cardiac events from a population of 114647 children and young people aged 17 or younger and newly treated with methylphenidate at any time in 2008-11. There were 864 patients with arrhythmias, 396 with hypertension, 52 with myocardial infarctions, 67 with stroke, and 44 with heart failure. The authors asked whether these events were more likely to occur in the first two months (and even smaller intervals) of methylphenidate use than in periods of non-use.

Cases of arrhythmia were $61 \%$ more likely to have occurred during the first two months of use than other periods of non-use (incidence rate ratio $1.61,95 \%$ confidence interval 1.48 to 1.74 , indicating that the increase in risk could lie between $48 \%$ and $74 \%$ ), and risk was even higher in the first three days of use (2.01, 1.74 to 2.31 ). The risk was increased for children taking doses above and below $27 \mathrm{mg}$ - a moderate dose-and was more pronounced among children who received healthcare for congenital heart disease in the six months before starting methylphenidate (3.49, 2.33 to 5.22). An increased risk for myocardial infarction appeared after the first week of treatment $(2.50,1.49$ to 4.20$)$ and persisted over two months. Cases of hypertension, ischemic stroke, and heart failure did not seem to be over-represented in the two months after the start of treatment with methylphenidate.

At first glance, these new data seem at odds with results from cohort studies in US Medicaid and private health insurance databases. ${ }^{5-7}$ Large analyses of over 200000 children with a diagnosis of ADHD found no difference in rates of adverse cardiovascular events in children who started taking methylphenidate compared with those who did not, regardless of whether children with pre-existing cardiovascular disease were included. While potential biases in either design could explain the discrepancy, it must also be noted that the case only study here and the earlier cohort studies ask different questions. The cohort studies ask about "cumulative effects,"- that is, did cardiovascular events occur more often among those who started taking methylphenidate than among those who did not? In contrast, the case only study asks about "triggering effects,"- that is, did patients experience an adverse cardiovascular event near the start of their drug treatment more often than during other periods, either before starting methylphenidate or after stopping it. ${ }^{8}$ As the authors say, their study asks "why now?" not "why me?"

Implicitly, the triggering effect reported by Shin and colleagues concerns children with a high risk of serious cardiovascular events. Indeed, their participants differed from those in the cohort studies. Among those with arrhythmia, there was about five times the prevalence of congenital heart disease $(5 \% \mathrm{v}$ $0.8 \%$ ) and two and a half times the prevalence of use of antipsychotics (13\% v 5\%). Antipsychotic drugs can prolong the QTc interval, which, in rare circumstances, can lead to an unstable arrhythmia and sudden death.

It is difficult to characterize the absolute risk in a case only study design. But in a population based study of children surgically treated for a congenital heart defect, the annual rate of sudden cardiac death over 20 years ranged from one case per 454 children to one case per 7154 children, depending on the type of defect. ${ }^{10}$ The findings of Shin and colleagues suggest that, among this subgroup, the rate could be increased up to threefold during the first few days of methylphenidate use, as the drug is associated with a threefold increased risk of arrhythmia in children with congenital heart disease. In the average child, the risk of serious cardiovascular events is extremely small (3 per 100 000) and any absolute increase associated with methylphenidate is also likely to be small. Regulatory labeling and treatment guidelines for stimulants express caution for use in children with personal or familial 
history of cardiovascular disease and call for routine monitoring of blood pressure. ${ }^{11} 12$ The study by Shin and colleagues underscores the need to consider the severity of ADHD symptoms and the option of non-stimulants for children with high cardiovascular risk, to avoid uses that are entirely off label, and to closely monitor patients for whom stimulants are critical for their wellbeing and development.

I acknowledge helpful comments from Deborah Blacker, who read an earlier version of this manuscript, and from the parents of a child with tetralogy of Fallot. The parents clarified the text, asked for additional information relevant for families, and reviewed the manuscript before submission.

Competing interests: I have read and understood the BMJ Group policy on declaration of interests and declare the following interests: none.

Provenance and peer review: Commissioned; not externally peer reviewed.

1 Chai G, Governale L, McMahon AW, Trinidad JP, Staffa J, Murphy D. Trends of outpatient prescription drug utilization in US children, 2002-2010. Pediatrics 2012;130:23-31. doi: 10.1542/peds.2011-2879 pmid:22711728.

2 Munk K, Gormsen L, Kim WY, Andersen NH. Cardiac Arrest following a Myocardial Infarction in a Child Treated with Methylphenidate. Case Rep Pediatr 2015;2015:905097. doi:10.1155/2015/905097 pmid:26221559.

3 Martinez-Raga J, Knecht C, Szerman N, Martinez MI. Risk of serious cardiovascular problems with medications for attention-deficit hyperactivity disorder. CNS Drugs 2013;27:15-30. doi:10.1007/s40263-012-0019-9 pmid:23160939.
4 Ju-Young S, Roughead L, Park B-J, Pratt N. Cardiovascular safety of methylphenidate among children and young people with attention-deficithyperactivity disorder (ADHD): nationwide self controlled case series study. BMJ 2016;353:i2550.

5 Winterstein AG, Gerhard T, Kubilis P, et al. Cardiovascular safety of central nervous system stimulants in children and adolescents: population based cohort study. BMJ 2012;345:e4627. doi:10.1136/bmj.e4627 pmid:22809800.

6 Schelleman H, Bilker WB, Strom BL, et al. Cardiovascular events and death in children exposed and unexposed to ADHD agents. Pediatrics 2011;127:1102-10. doi:10.1542/ peds.2010-3371 pmid:21576311.

7 Cooper WO, Habel LA, Sox CM, et al. ADHD drugs and serious cardiovascular events in children and young adults. N Engl J Med 2011;365:1896-904. doi:10.1056/ NEJMoa1110212 pmid:22043968.

8 Maclure M, Fireman B, Nelson JC, et al. When should case-only designs be used for safety monitoring of medical products? Pharmacoepidemiol Drug Saf 2012;21(Suppl 1):50-61. doi:10.1002/pds.2330 pmid:22262593.

9 Maclure M. 'Why me?' versus 'why now?'--differences between operational hypotheses in case-control versus case-crossover studies. Pharmacoepidemiol Drug Saf 2007;16:850-3. doi:10.1002/pds.1438 pmid:17636552.

9 Silka MJ, Hardy BG, Menashe VD, Morris CD. A population-based prospective evaluation of risk of sudden cardiac death after operation for common congenital heart defects. $J$ Am Coll Cardiol 1998;32:245-51. doi:10.1016/S0735-1097(98)00187-9 pmid:9669277.

10 Dulcan MK, Benson RS. AACAP Official Action. Summary of the practice parameters for the assessment and treatment of children, adolescents, and adults with ADHD. J Am Acad Child Adolesc Psychiatry 1997;36:85S-121S. doi:10.1097/00004583-19971000100007 pmid:9291734.

11 Westover AN, Halm EA. Do prescription stimulants increase the risk of adverse cardiovascular events?: A systematic review. BMC Cardiovasc Disord 2012;12:41. doi: 10.1186/1471-2261-12-41 pmid:22682429.

Published by the BMJ Publishing Group Limited. For permission to use (where not already granted under a licence) please go to http://group.bmj.com/group/rights-licensing/ permissions

This is an Open Access article distributed in accordance with the Creative Commons Attribution Non Commercial (CC BY-NC 3.0) license, which permits others to distribute, remix, adapt, build upon this work non-commercially, and license their derivative works on different terms, provided the original work is properly cited and the use is non-commercial. See: http://creativecommons.org/licenses/by-nc/3.0/. 